\title{
Precipitins with relevance to farmer's lung and aspergillosis in normal and other sera ${ }^{1}$
}

\author{
J. E. JAMESON \\ From the Public Health Laboratory, Brighton
}

SYNOPSIS Immunodiffusion, immunoosmophoresis, and precipitin inhibition tests were carried out on various categories of sera with extracts of Micropolyspora faeni (Thermopolyspora polyspora), Aspergillus fumigatus, and Thermoactinomyces vulgaris. The sera were from clinical cases of farmer's lung, from symptomless farm workers, from expectant mothers, from tuberculous and from asthmatic patients, and from patients with miscellaneous lung disorders. The clinical cases of farmer's lung became divisible into two groups by serological tests for antibody to a particular soluble antigenic component of $M$. faeni. The suggestion is made that one of these two groups of cases may be aetiologically unrelated to $M$. faeni. One of six sera tested in this group reacted strongly with an extract of $T$. vulgaris. Antibodies to certain components of some extracts of $M$. faeni and of $A$. fumigatus were found in a high proportion of normal sera. Possible reasons for this finding have been given.

Precipitins may be demonstrated by immunoosmophoresis in sera found negative by conventional immunodiffusion tests. One to three arcs of precipitation were demonstrated in nine of 16 such sera from clinical cases of farmer's lung (Jameson, 1968). The aim of this work was to ascertain the prevalence of similar antibody levels in sera of various categories, and to obtain any other information which might be relevant to the serological diagnosis of farmer's lung or of allergic aspergillosis.

\section{MATERIALS AND METHODS}

IMMUNOOSMOPHORESIS This was carried out as previously described (Jameson, 1968). The identical extracts of Micropolyspora faeni (Thermopolyspora polyspora) were used at the same dilutions. A fractionation of $M$. faeni antigen through a column of Sephadex $G 150$ was also used, as were four dilutions ( $20 \mathrm{~N}, 5 \mathrm{~N}, \mathrm{~N} / 1$, and $\mathrm{N} / 6$ ) of a broth culture extract of $A$. fumigatus (see under antigens). The separation between serum slots and antigen strips was $\frac{5}{8}$ in. $(16 \mathrm{~mm})$.

IMMUNODIFFUSION Agar-coated slides were placed in Perspex holders. Molten $1 \%$ Ionagar no. 2 (Oxoid) in Tris-saline buffer at $p H \mathbf{H} 4$ (Crowle, 1961) was poured over them to a depth of $2 \mathrm{~mm}$ and allowed to set. By means of a jig and cutters which allowed holes to be cut

'A report to the working party on farmer's lung of the Public Health Laboratory Service.

Received for publication 31 December 1968. accurately, four serum reservoirs of $8 \mathrm{~mm}$ diameter were cut in each agar slide; each serum reservoir was surrounded by six equally spaced antigen reservoirs of $4 \mathrm{~mm}$ diameter. The separation between the serum and antigen reservoirs was $2.5 \mathrm{~mm}(8.5 \mathrm{~mm}$ between centres). Charged slides were incubated at $25^{\circ} \mathrm{C}$ in a moist chamber for 24 hours. Washing and staining were as for immunoosmophoresis (Jameson, 1968).

PRECIPITIN INHIBITION TEST The following modification of the precipitin inhibition test (Ray and Kadull, 1964 and 1965; Ray and Converse, 1967) was used.

Using a special cutter, wells for sera and antigens were cut in an agar slide prepared as in the immunodiffusion tests. The layout is shown in the Figure. Doubling dilutions of the broth culture extract of $M$. faeni were set up by chess board titration with doubling dilutions of a standard serum and incubated for 20 hours at $25^{\circ} \mathrm{C}$. The minimum reacting concentration of the antigen was ascertained and is definable as the minimum concentration of the antigen which was capable of yielding a clear single arc of precipitation with any dilution of the serum. That optional dilution of the serum is referred to as the minimum reacting dilution. The arc produced by the interaction of the minimum reacting dilution and concentration was barely visible in unstained preparations, but when stained the arc was sharp and clearly defined. In the test proper, six tests were set up per agar slide, and there were three controls (see Fig.). The minimum reacting dilution of the standard serum was added to each of the three serum wells, and the minimum reacting concentration of the antigen was added to the three corresponding antigencontrol wells. The remaining antigen wells were filled 


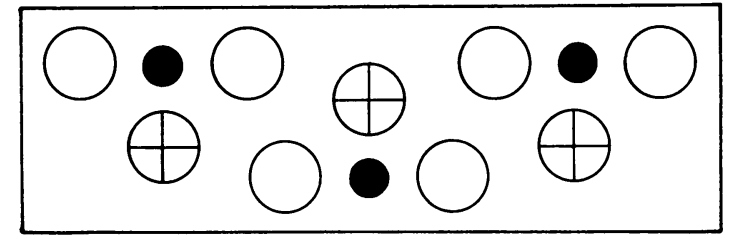

FIG. The layout of the precipitin inhibition test.

with mixtures of equal parts of undiluted test sera and $M$. faeni antigen at twice its minimum reacting concentration. The latter reactant mixtures were well mixed before adding to their appropriate antigen wells. Neither the standard serum nor the test serum-antigen mixtures were preincubated, and the conditions of the tests were thus identical with those in the preliminary titrations.

Any serum which failed to show an arc continuous with the arc yielded by its adjacent antigen control was regarded as positive. All positive tests were repeated with undiluted and with serial doubling dilutions of the positive test sera, so as to ascertain their endpoint dilutions.

ANTIGENS An $A$. fumigatus broth culture extract was prepared by a method similar to that used in the $M$. faeni extract, excepting that the yield was harvested after four weeks at $37^{\circ} \mathrm{C}$.

MYCELIAL EXTRACTS Mycelial extracts of $A$. fumigatus, Micropolyspora faeni, and Thermoactinomyces vulgaris were prepared from homogenized sonicated mycelium as described in a preliminary study by a Working Party of the Public Health Laboratory Service (1967). The sonicated extracts were precipitated with 2 volumes of acetone and harvested as soon as dense precipitates formed. The methods of cultivation of the mycelia were as follows:

A. fumigatus In litre flasks containing $200 \mathrm{ml}$ of glucose peptone broth, at $37^{\circ} \mathrm{C}$ for two to three weeks.

$M$. faeni On nutrient agar at $45^{\circ}$ to $50^{\circ} \mathrm{C}$ for two to five days (until growth is good).

T. vulgaris As for $M$. faeni, cultivation at $42^{\circ} \mathrm{C}$ (I. G. Murray, personal communication, 1968).

All of the above mycelial extracts were prepared in and received from the Mycological Reference Laboratory, London School of Hygiene and Tropical Medicine, Keppel Street, London, W.C.1. They were reconstituted in $0.85 \%$ saline. $(\mathrm{N} / 1=$ contents of one ampoule in $1 \mathrm{ml}$ etc.) The normalities of the broth culture extracts were arbitrarily assigned.

SEPHADEX FRACTIONATION A concentrated extract of M. faeni, $0.5 \mathrm{ml}$, was run through a column of Sephadex G 150. Traces of soluble antigens of $M$. faeni were

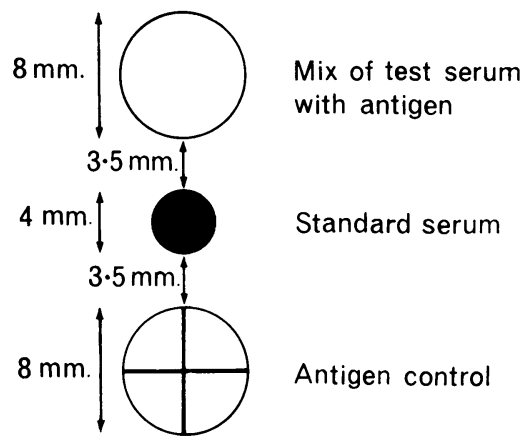

detected within a range of 15 fractions, each of about $10 \mathrm{ml}$. By use of a fraction collector, the same procedure was carried out on 12 occasions. The 12 first, second? third, etc, fractions were pooled. The pooled fractions 1 to 15 were concentrated approximately sixfold b\& evaporation and were then tested by immunodiffusio and by electrophoretic methods. The A1 component of the antigen (see Discussion) was spread over a wide range of fractions (5 to 11) than any other antigen that was detected by serological methods. Fractions $7,8,9$ all rich in A1, were pooled and further concentrated. This pool is referred to as the Sephadex fractionation. A 1/64 dilution of the Sephadex fractionation was used in th: immunoosmophoresis tests.

SERA A main group and two subsidiary groups of ser\& were tested. The main body (group A) of 147 sera wa composed as follows: 80 sera from expectant mothers?

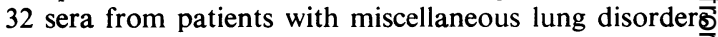
other than farmer's lung; 18 sera from patients with pulB monary tuberculosis; and 17 sera from asthmatic patients Group A sera were received from the Pathology Departe. ment of the Royal Sussex County Hospital and from local chest physicians. A second group (group B) como prised 24 sera from clinical cases of farmer's lung, and third (group C) 23 positive sera from symptomless farp. workers. All sera in group $\mathrm{C}$ and all but two in group 8 were received from other laboratories; they were thus selected sera.

TESTS Excepting in instances when quantities of serf were insufficient for all of the tests, group A sera were. tested by immunoosmophoresis against the dialysate and against four concentrations $(2 \cdot 5 \mathrm{~N}, \mathrm{~N} / 2, \mathrm{~N} / 16 \text {, and } \mathrm{N} / 64)^{\circ}$ of the broth culture extract of $M$. faeni, and also agains four concentrations $(2 \mathrm{ON}, 5 \mathrm{~N}, \mathrm{~N} / 1$, and N/6) of the brot: culture extract of $A$. fumigatus. They were tested bळ immunodiffusion against the dialysate and the $2 \cdot 5 \mathrm{~N}, \mathrm{~N} / \mathrm{K}$ $\mathrm{N} / 4, \mathrm{~N} / 16$, and N/64 concentrations of the broth culture extract of $M$. faeni. Additional tests were carried out of those sera which reacted with $M$. faeni in any of the above tests. The additional tests were the precipitin inhibition test, osmophoresis against Sephadex fractionation N/64 and immunodiffusion against $A$. fumigatus $5 \mathrm{~N}$. The ser in groups B and C from clinical cases of farmer's lung an 
from symptomless farm workers, respectively, were tested against $M$. faeni by all the tests above, but no tests were made with them against $\boldsymbol{A}$. fumigatus. All group C sera and six group B sera were also tested by immunodiffusion against $T$. vulgaris.

\section{RESULTS}

Tests by osmophoresis and immunodiffusion on group A sera are set out in Tables I to IV. Table III shows the interrelationship which existed in group A sera between reactors to $M$. faeni and reactors to $A$. fumigatus. Of 82 sera which yielded one or more arcs with $M$. faeni, 72 reacted similarly with $A$. fumigatus. Among 65 sera not reacting with $M$. faeni, 39 reacted with $A$. fumigatus. Tables $\mathrm{V}$ and VI set out the results by immunodiffusion and immunoosmophoresis on the individual sera in groups B and C. The results of tests on all three groups of sera by the precipitin inhibition test, by immunoosmophoresis

TABLE I

PERCENTAGES OF POSITIVE TESTS ON GROUP A SERA BY IMMUNOOSMOPHORESIS AGAINST $M$. faeni

M. faeni

Extracts Sera

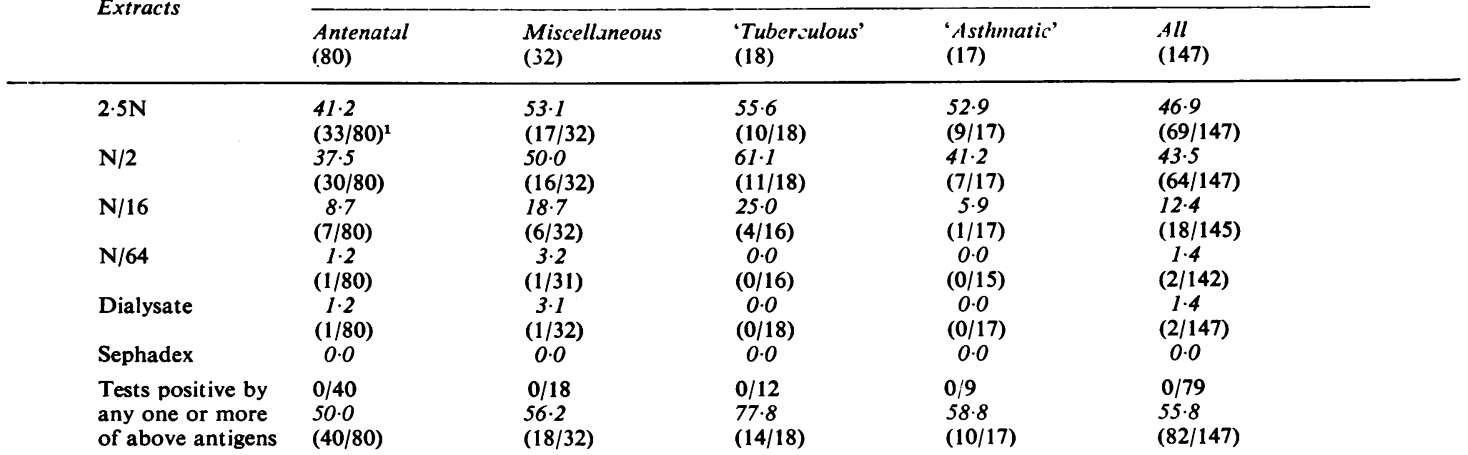

${ }^{1}$ Numerators and denominators.

TABLE II

PERCENTAGES OF POSITIVE TESTS ON GROUP A SERA BY IMMUNOOSMOPHORESIS AGAINST A. fumigatus

\begin{tabular}{|c|c|c|c|c|c|}
\hline \multirow{2}{*}{$\begin{array}{l}\text { A. fumigatus } \\
\text { Extracts }\end{array}$} & \multicolumn{5}{|l|}{ Sera } \\
\hline & $\begin{array}{l}\text { Antenatal } \\
(80)\end{array}$ & $\begin{array}{l}\text { Miscellaneous } \\
\text { (32) }\end{array}$ & $\begin{array}{l}\text { 'Tuberculous' } \\
\text { (18) }\end{array}$ & $\begin{array}{l}\text { 'Asthmatic' } \\
\text { (17) }\end{array}$ & $\begin{array}{l}\text { All } \\
(147)\end{array}$ \\
\hline $20 N$ & $\begin{array}{l}70 \cdot 0 \\
(56 / 80)^{1}\end{array}$ & $\begin{array}{l}75 \cdot 0 \\
(24 / 32)\end{array}$ & $\begin{array}{l}77 \cdot 8 \\
(14 / 18)\end{array}$ & $\begin{array}{l}70 \cdot 6 \\
(12 / 17)\end{array}$ & $\begin{array}{l}72 \cdot 1 \\
(106 / 147)\end{array}$ \\
\hline $5 N$ & $\begin{array}{l}50 \cdot 0 \\
(40 / 80)\end{array}$ & $\begin{array}{l}59.4 \\
(19 / 32)\end{array}$ & $\begin{array}{l}72 \cdot 2 \\
(13 / 18)\end{array}$ & $\begin{array}{l}52.9 \\
(9 / 17)\end{array}$ & $\begin{array}{l}55 \cdot 1 \\
(81 / 147)\end{array}$ \\
\hline $\mathbf{N}$ & $\begin{array}{l}36 \cdot 2 \\
(29 / 80)\end{array}$ & $\begin{array}{l}46.9 \\
(15 / 32)\end{array}$ & $\begin{array}{l}61 \cdot 1 \\
(11 / 18)\end{array}$ & $\begin{array}{l}35 \cdot 3 \\
(6 / 17)\end{array}$ & $\begin{array}{l}41 \cdot 5 \\
(61 / 147)\end{array}$ \\
\hline N6 & $\begin{array}{c}5.0 \\
(4 / 80)\end{array}$ & $\begin{array}{l}15 \cdot 6 \\
(5 / 32)\end{array}$ & $\begin{array}{l}12 \cdot 5 \\
(2 / 16)\end{array}$ & $\begin{array}{c}23 \cdot 5 \\
(4 / 17)\end{array}$ & $\begin{array}{l}10 \cdot 3 \\
(15 / 145)\end{array}$ \\
\hline $\begin{array}{l}\text { Tests positive by } \\
\text { any one or more } \\
\text { of above antigen } \\
\text { dilutions }\end{array}$ & $\begin{array}{l}73 \cdot 7 \\
(59 / 80)\end{array}$ & $\begin{array}{l}78 \cdot 1 \\
(25 / 32)\end{array}$ & $\begin{array}{l}83 \cdot 3 \\
(15 / 18)\end{array}$ & $\begin{array}{l}70 \cdot 6 \\
(12 / 17)\end{array}$ & $\begin{array}{l}75 \cdot 5 \\
(111 / 147)\end{array}$ \\
\hline
\end{tabular}

${ }^{1}$ Numerators and denominators.

TABLE III

ANALYSIS OF COMBINED RESULTS ON GROUP A SERA BY IMMUNOOSMOPHORESIS AGAINST $M$. faeni AND $A$. fumigatus

\begin{tabular}{|c|c|c|c|c|c|c|c|c|c|c|}
\hline \multirow{4}{*}{$\begin{array}{l}\text { Nos. } \\
\text { Sera Positive } \\
\text { and Negative } \\
\text { Against M. faeni }\end{array}$} & \multicolumn{10}{|l|}{ Sera } \\
\hline & \multicolumn{2}{|l|}{ Antenatal } & \multicolumn{2}{|c|}{ Miscellaneous } & \multicolumn{2}{|c|}{ 'Tuberculous' } & \multicolumn{2}{|c|}{ 'Asthmatic' } & \multicolumn{2}{|l|}{ All } \\
\hline & \multicolumn{10}{|c|}{ Numbers of Sera Positive or Negative Against A. fumigatus Fxtract } \\
\hline & + & - & + & - & + & - & + & - & + & - \\
\hline+ & $\begin{array}{l}34 \\
25\end{array}$ & $\begin{array}{r}6 \\
15\end{array}$ & $\begin{array}{r}16 \\
9\end{array}$ & $\begin{array}{l}2 \\
5\end{array}$ & $\begin{array}{r}13 \\
2\end{array}$ & $\begin{array}{l}1 \\
2\end{array}$ & $\begin{array}{l}9 \\
3\end{array}$ & $\begin{array}{l}1 \\
4\end{array}$ & $\begin{array}{l}72 \\
39\end{array}$ & $\begin{array}{l}10 \\
26\end{array}$ \\
\hline
\end{tabular}


TABLE IV

PERCENTAGES OF POSITIVE TESTS ON GROUP A SERA BY IMMUNODIFfUSION AGAINST $M$. faeni AND $A$. fumigatus

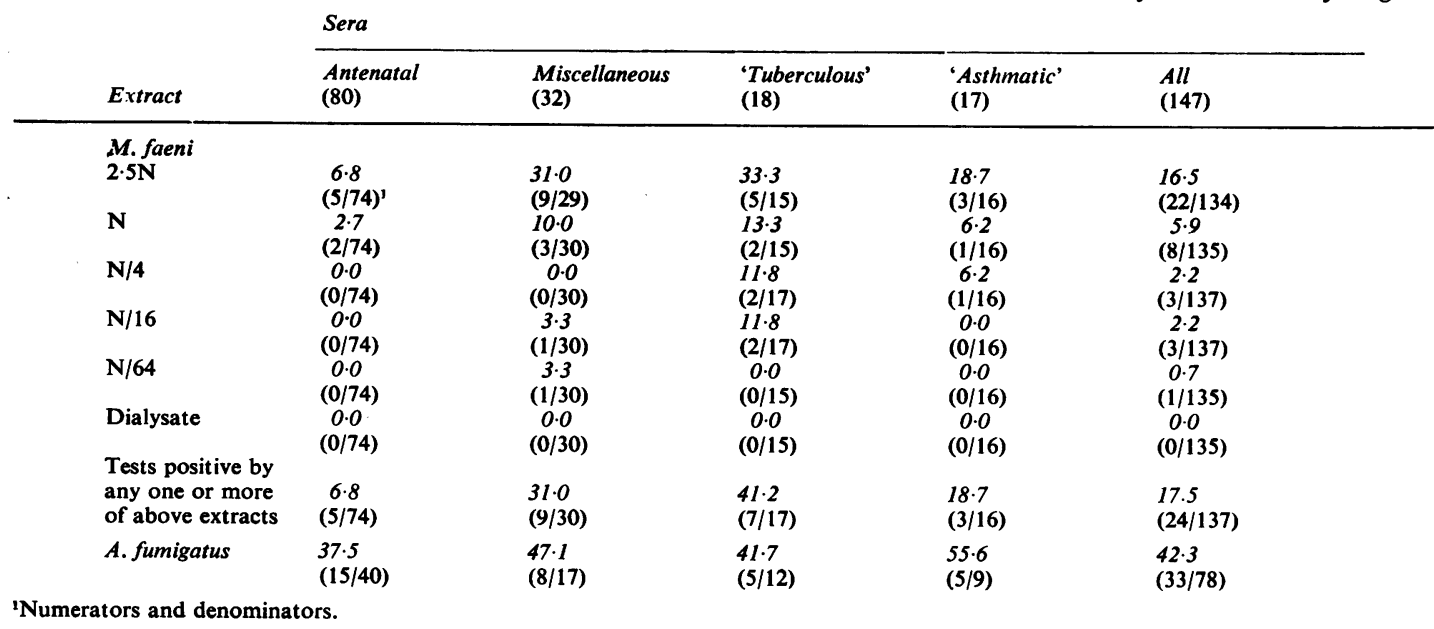

TABLE V

RESULTS OF TESTS BY IMMUNODIFFUSION AND IMMUNOOSMOPHORESIS ON INDIVIDUAL SERA IN GROUP B2 (CLINICALLY FARMER'S LUNG)

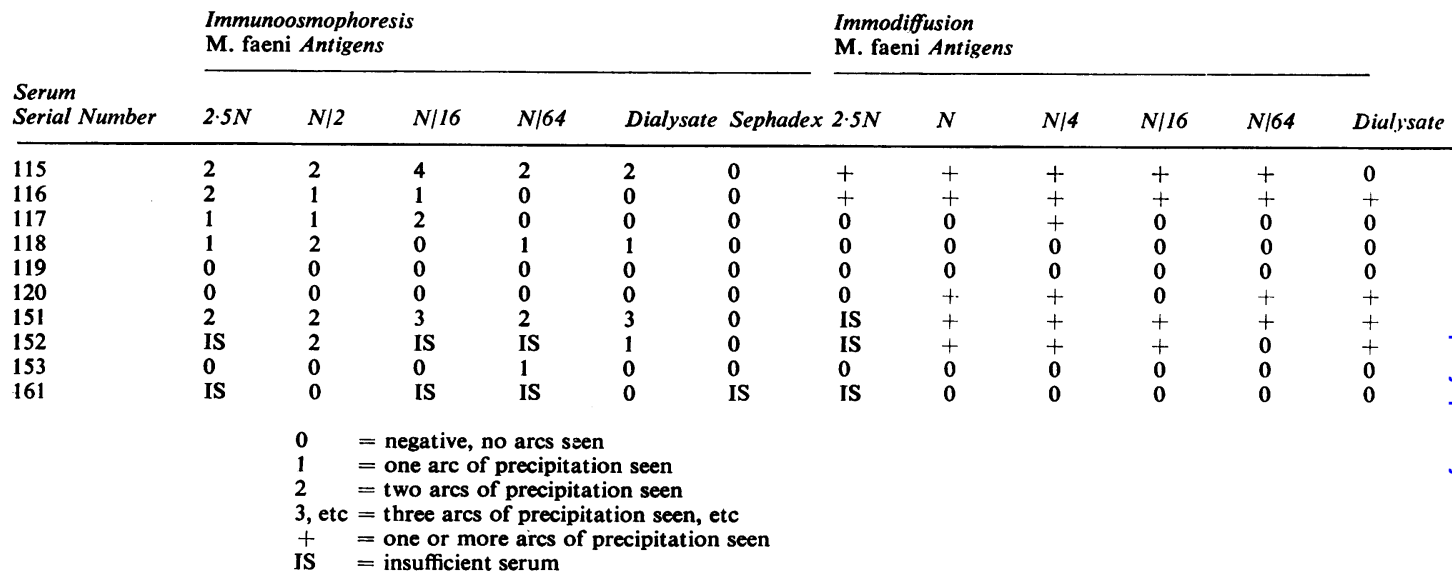

with Sephadex fractionation, with the dialysate, and with the N/64 concentration of M. faeni, are set out in Table VII.

Approximately $56 \%$ of all sera in group A yielded one or more arcs of precipitation by immunoosmophoresis with the broth culture extract of $M$. faeni. The percentages of positive reactors in all the sera, except from cases of tuberculosis, fell progressively with the use of increasing dilutions of the extract. The tuberculous sera yielded the highest proportion of reactors (approximately $61 \%$ ) with the $\mathrm{N} / 2$ dilution. Two sera in group A reacted with the N/64 dilution and two others reacted with the dialysate of $M$. faeni. No serum in group A reacted with
Sephadex fractionation. The highest proportion of reactors to $M$. faeni (approximately $78 \%$ ) was found in the sera from tuberculous patients, and the lowest as might be expected, in the sera of expectant mothers $(50 \%)$. An even higher overall incidence ot reactors was found to $A$. fumigatus (approximatel $75 \%$ : Table II). As in the case with $M$. faeni, the tuberculous sera provided the highest proportion of reactors to $A$. fumigatus (approximately $83 \%$ ), an f $^{\circ}$ the proportions also fell progressively with the use of increasing dilutions of the $A$. fumigatus antigen? More than two arcs of precipitation with $M$. faen were seen in only five sera. In each of these, three arcs were seen. Four of these five sera were in the 
TABLE VI

RESULTS OF TESTS BY IMMUNODIFFUSION AND IMMUNOOSMOPHORESIS IN INDIVIDUAL SERA IN GROUP C (CLINICALLY NOT FARMER'S LUNG)

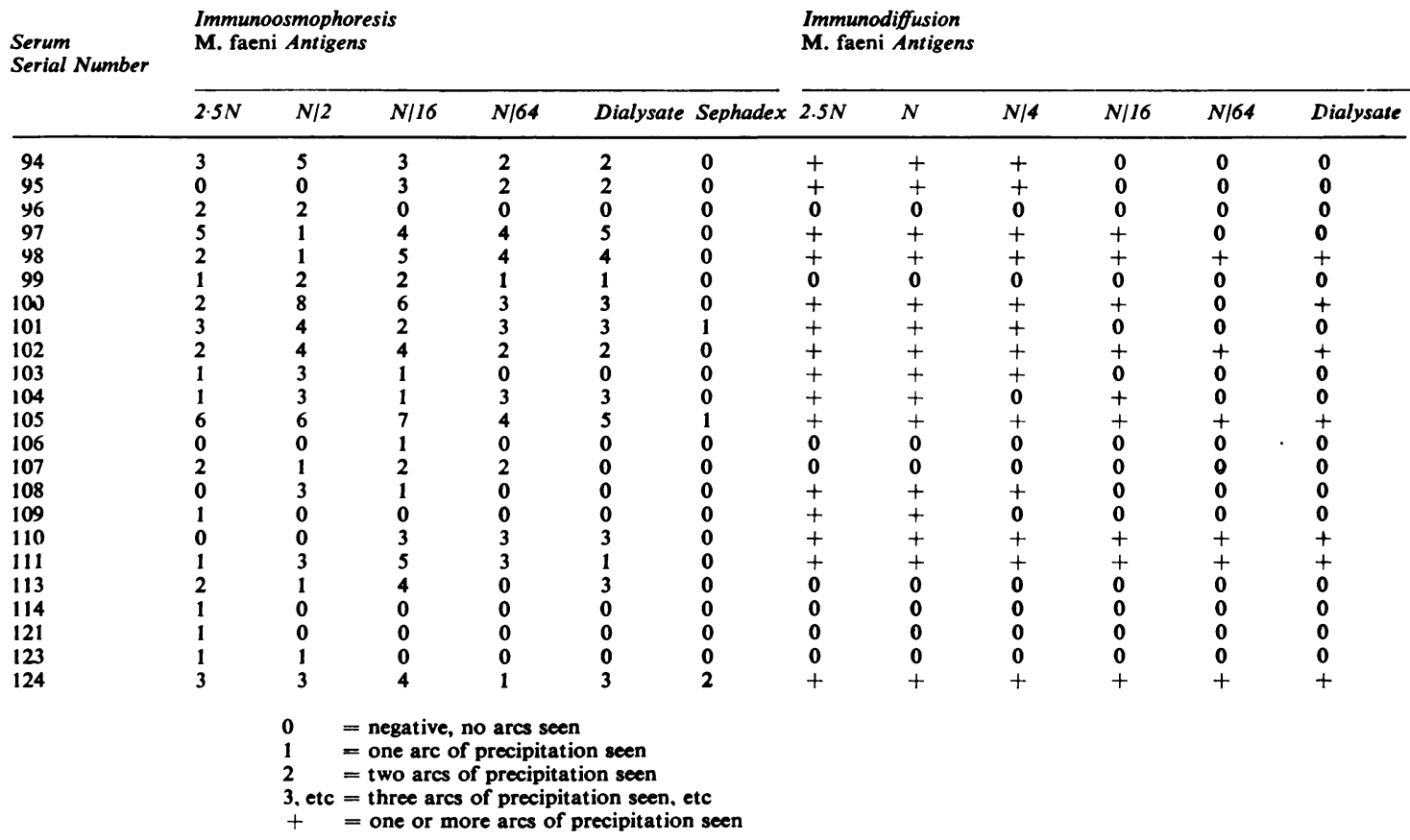

TABLE VII

PROPORTIONS OF POSITIVE REACTIONS IN ALL GROUPS OF SERA BY FOUR TESTS

Precipitin

Inhibition Test

(Undiluted Serum)

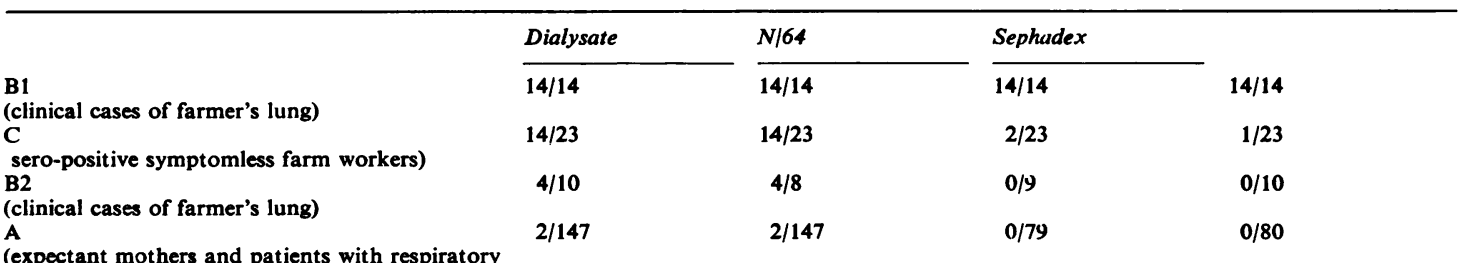

(expectant mothers and patients with respiratory disorders other than farmer's lung)

miscellaneous group, the fifth was from an asthmatic. A total of 36 sera in group A, 14 of which were antenatal, showed more than two arcs of precipitation with the highly concentrated $A$. fumigatus extract $(2 \mathrm{ON})$. Four of these sera, two of which were from expectant mothers, showed five arcs. No serum showed more than five arcs with any concentration of $A$. fumigatus extract.

Results of the immunodiffusion tests on group A sera are set out in Table IV. As with immunoosmophoresis, an unexpectedly high proportion of reactors was found by the use of concentrated antigens
(M. faeni approximately $17 \%, A$. fumigatus approximately $42 \%)$. The tests with $A$. fumigatus were on selected sera, namely, sera which reacted with $M$. faeni. The group of sera from cases of tuberculosis again provided the highest proportion of reactors to $M$. faeni (approximately $41 \%$ ).

Fourteen of the 24 sera from clinical cases of farmer's lung reacted by the precipitin inhibition test and, usually strongly, by all of the other tests with $M$. faeni. These 14 sera have been assigned to a subgroup B1. The remaining 10 sera (subgroup B2) failed to react by the precipitin inhibition test, and 
in at least one of the other tests with $M$. faeni (Table V). The precipitin inhibition test (with undiluted serum) was negative in all sera in group $A$ and in all but one (Table VI, no. 105) of the sera in group C. Endpoint dilutions in the positive precipitin inhibition tests were as follows: $\frac{1}{2}$, serum 105 and four sera in group B1; $\frac{1}{4}$, six sera in group $B 1 ; \frac{1}{8}$, one serum in group $B 1 ; 1 / 16$, three sera in group $B 1$.

One of six sera in group B2 (Table V, no. 118) reacted strongly by immunodiffusion with all three dilutions of the $T$. vulgaris extract. None of the symptomless farm workers (group C) reacted positively by this test.

\section{DISCUSSION}

The incidence of reactors in group A sera to M. faeni and $A$. fumigutus was much higher than previously reported (Pepys, Riddell, Citron, Clayton, and Short, 1959; Pepys, Riddell, Citron, and Clayton, 1962; Voisin, Biguet, Tran Van Ky, Schouller, Sergeant, and Gernez-Rieux, 1964; Pepys and Jenkins, 1965; British Tuberculosis Association, 1968). Two factors are likely to have contributed. The use of highly concentrated antigenic extracts could be expected to result in certain antigens manifesting, which might otherwise have been too diluted to reveal their presence. Thus when the results of the tests with the $2.5 \mathrm{~N}$ and $\mathrm{N} / 1$ concentrations of the $M$. faeni extract are deleted from Table IV, the remaining findings more or less tally with those of other workers. It is also probably that the use, as antigen, of broth culture extracts, was a second factor. When 20 of the sera in group A which had reacted with $M$. faeni by immunodiffusion were retested with three dilutions (N/1, N/4, and N/16) of a mycelial extract of $M$. faeni, only three sera reacted with the $\mathrm{N} / 1$ mycelial extract, and only one with the N/4 mycelial extract. Though this difference could have been attributable to the broth culture extract having been substantially more concentrated than the mycelial extract, collateral tests with group B1 sera did not corroborate that explanation. Thus one is led to the conclusion that antigens capable of reacting with group A sera were richer, absolutely and relatively, in the broth culture extract. Similar evidence was found respecting the broth culture extract of $A$. fumigatus. When seven reacting sera from expectant mothers were retested by immunodiffusion against two mycelial extracts of $A$. fumigatus, all seven failed to react with one, and only one reacted with the other, mycelial extract. That these positive reactions with the broth culture extract were not attributable to C-substance (Longbottom and Pepys, 1964) was shown by their persistence in further immunodiffusion tests in agar buffered at $p \mathrm{H} 7$ with a phosphate-citrate buffer. A more disturbing feature was that when immunodiffusion tests on these seven sera were repeated with a $\overline{\bar{s}}$ further broth culture extract of $A$. fumigatus, only one serum reacted, as in the case with one of the two 들 mycelial extracts. It is not known for certain whether or not both broth culture extracts were made from $\Phi$ the identical strain of $A$. fumigatus. The only known difference in the manner in which the two broth ${ }^{\text {s }}$ culture extracts were prepared is that the latter was $\vec{O}$ harvested after five weeks as against four weeks in the former.

It is shown in Table III that any group A serum which reacted with $M$. faeni was more likely to react with $A$. fumigatus, and vice versa. This might be due $N$ to common environmental factors predisposing to $G$ exposure to both allergens: alternatively there may $\vec{\bullet}$ be an antigen common to both allergens in con- 0 centrated broth culture extracts. A similar minor antigenic link between Mycobacterium tuberculosis os and $M$. faeni might possibly explain why the tuber- $\frac{\mathbb{D}}{O}$ culous sera provided a higher proportion of reactors to $M$. faeni than any others in group A though it $\frac{\partial}{\sigma}$ seems more probable that lung tissue damaged by $M$. tuberculosis provides sites for the lodgment and $\vec{\theta}$ proliferation of $M$. faeni, as it does for fungi.

Only one serum (Table V, no. 120) reacted with any one extract by immunodiffusion and not by immunoosmophoresis. By conventional electrophoresis this serum exhibited a single arc in the $\mathrm{C}$ region (Pepys, Jenkins, Festenstein, Gregory, Lacey, and Skinner, 1963). Although one or more arcs may sometimes be seen on the cathodic side of the antigen strip following immunoosmophoresis, obviously no precipitation can result from any $\mathrm{C}$ antigen which is carried, during immunoosmophoresis, more quickly towards the cathode than the serum globulins.

The differences in the reactions of the sera in the various groups to four particular tests against $M$. faeni (Table VlI) require discussion. The precipitin $\delta$ inhibition test was the most useful single test in $₹$ discriminating group B1 sera from the remainder. 0 Immunoosmophoresis against Sephadex fractionation provided nearly as good discrimination, while immunoosmophoresis against the dialysate and against the $\mathrm{N} / 64$ dilutions were less discriminatory, or though still more discriminatory than tests with the $N$ more concentrated extracts of $\boldsymbol{M}$. faeni. This func- N tional grading between these four tests seems to run $\sigma$ parallel with the antigenic specificity of the tests, and requires explanation. Multiple arcs of precipitation are demonstrable by immunodiffusion tests with $\stackrel{\oplus}{\rightarrow}$ concentrated extracts of $M$. faeni. Progressive dilu- 0 tion of an extract results in a reduction in the number of arcs until a single arc is normally demon- $\mathbb{D}$

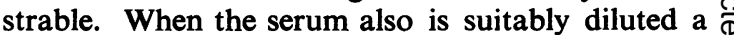
single arc can usually be demonstrated by the 
use of a still higher dilution of the extract (the minimum reacting concentration). Owing to the effects of reactant excesses in multiple antigen antibody systems, the latter single arc may not necessarily result from the same antigen as the former. A minimum reacting concentration of a polyvalent antigen which yields a single arc of precipitation with a strongly reacting serum may show two (or more) arcs with another serum. For all these reasons the precipitin inhibition test has an advantage in specificity over all the other tests used here because a single arc of precipitation in this test results invariably from the interaction of the same minimum reacting concentration with the same minimum reacting dilution. The antigenic component of the polyvalent antigen contributing to this single arc was shown by conventional electrophoresis to be an A antigen (Pepys et al, 1963). Most polyvalent extracts of $M$. faeni with which $I$ have worked are particularly rich in this antigen, which I will call the A1 antigen. As the Sephadex fractionation was selected for its richness in A1 antigen, it was necessarily richer in that component than the whole antigen from which it had been fractionated. Moreover the concentration of Sephadex used $(\mathrm{N} / 64)$ was near to its minimum reacting concentration by immunoosmophoresis, although this concentration was also capable of reacting with high titre antisera. With the latter sera, though the central parts of the resultant arcs were inhibited by excess antibody, precipitation occurred in those regions where the antibody concentrations were lower, namely, at the extreme ends of the arcs. Immunoosmophoresis with Sephadex, in distinction from the dialysate and from the N/64 concentration of the broth culture extract, resulted in the production of more than one arc in one instance only (Table VI, no. 124).

The similarities observed here between the reactions by immunoosmophoresis with the dialysate and with the N/64 concentration shed further light on the antigenic constitution of the former. It was previously suspected (Jameson, 1968) that the dialysate might be antigenically distinct. The differences previously observed in the reactions given by the dialysate and the broth culture extract of $M$. faeni are, however, also amenable to a quantitative explanation. Although this dialysate is a very highly concentrated fluid, the antigens in it may yet be comparable in concentration with those in the N/64 concentration of the broth culture extract. That small, undetected leakages do sometimes occur through dialysis membranes has been confirmed by further findings of soluble antigens in further dialysates of $M$. faeni extracts. Comparison by immunodiffusion tests of various antigen fractionations may similarly be misleading. In one such instance when concentration without fractionation of antigens had resulted, discontinuity was clearly established between arcs arising from two adjacent antigen fractions. The discontinuity of arcs was abolished by appropriate dilution of the more concentrated of the two antigen-containing fractions. Such hazards in interpretation are attributable to the effects of various reactant excesses in multiple antigen-antibody systems.

Division of the sera from the clinical cases of farmer's lung into two groups based on the results of serological tests may be considered artificial. The apparent absence of antibody to the A1 component of M. faeni in group B2 sera might, on the other hand, have aetiological significance. It is therefore tempting to postulate that group B2 cases may have been unrelated aetiologically with $M$. faeni. If so, other allergens must be presumed to have been responsible. One possible such allergen is $T$. vulgaris. The discovery of one serum in group B2 (out of six sera tested) which reacted strongly in immunodiffusion against $T$. vulgaris and the absence of any reactors with $T$. vulgaris in 23 symptomless farm workers suggests that there may be a case for a further search for alternative allergens in those clinical cases of farmer's lung which fall into group B2, namely, cases in which antibody to the A1 antigen of $M$. faeni is not demonstrable. Support for this suggestion is provided by the recent report by Riddle, Channell, Blyth, Weir, Lloyd, Amos, and Grant (1968) of a case of allergic alveolitis attributed to exposure to Aspergillus clavatus, and of similar cases attributed to Aspergillus fumigatus (Weir, personal communication, 1968).

It seems fair to conclude that within the normal population there is a distribution of precipitating antibodies which may react with two or three of the soluble antigens which may be found in concentrated broth culture extracts of $M$. faeni and $A$. fumigatus. Acetone-precipitated mycelial extracts were less rich in these unwanted components, though it does not necessarily follow that they might not also lack certain other components which might have some value. When precipitin tests are carried out with systems in which any or all of many different antigen-antibody unions may occur, clearly some individual unions carry more diagnostic significance than others. Union with the A1 component of $M$. faeni may be a significant one.

This work was assisted by a grant by the Ministry of Health to the working party on farmer's lung of the Public Health Laboratory Service. I am grateful to Dr I. G. Murray for his continual encouragement and for supplying strains of $M$. faeni, A. fumigatus, mycelial extracts, and sera. For supplying sera I am also indebted 
in particular to Drs F. Meade, B. Rigden, J. G. Wallace, D. M. Weir, and to the staff of the Stephen Ralli Laboratory.

\section{REFERENCES}

British Tuberculosis Association Research Committee (1968). Tubercle (Lond.), 49, 1.

Crowle, A. J. (1961). Immunodiffusion, Academic Press, New York, p. 302.

Jameson, J. E. (1968). J. clin. Path., 21, 376.

Longbottom, J. L., and Pepys, J. (1964). J. Path. Bact., 88, 141

Pepys, J., and Jenkins, P. A. (1965). Thorax, 20, 21.

$$
\text { , Festenstein, G. N., Gregory, P. H., Lacey, M. E., and }
$$
Skinner, F. A. (1963), Lancet, 2, 607.
-, Riddell, R. W., Citron, K. M., and Clayton, Y. M. (1962). Thorax, 17, 366

$\longrightarrow, \frac{1}{80}, \frac{1}{167}, \longrightarrow$, and Short, E. I. (1959). Amer. Rev. resp. Dis., $\overline{\bar{G}}$

Public Health Laboratory Service Working Party (1967). Mth. Bull. Minist. Hlth Lab. Serv., 26, 167. (1967b). Ibid, 15, 1049. and Converse, J. L. (1967). Ibid, 15, 1054

Ray, J. G. (1967). Appl. Microbiol., 15, 794.

-, Jr., and Kadull, P. J. (1964). Ibid. 12, 349. (1965). Ibid, 13, 925 .

Riddle, H. F. V., Channell, S., Blyth, W., Weir, D. M., Lloyd, M. Amos, W. M. G., and Grant, I. W. B. (1968), Thorax, 23, 271, Voisin, C., Biguet, J., Tran Van Ky, P., Schouller, A., Sergeant, Y. H., and Gernez-Rieux, C. (1964). Rev. Tuberc. (Paris), 28, 1311. 